\title{
Survival After Surgical Drainage of Malignant Pericardial Effusion
}

\author{
Lars Niclauss $\cdot$ Michael Montemurro • \\ René Prêtre
}

Published online: 24 February 2015

(c) Société Internationale de Chirurgie 2015

\begin{abstract}
Objectives Management of malignant pericardial effusion (PE) is complex. Cardiac surgeons are not necessarily familiar with or are challenged by the many underlying etiologies. Analyzing risk factors for mortality may help to estimate the benefit of surgery in high-risk patients.

Methods Patients undergoing a surgical pericardiotomy for malignant PE, between 2001 and 2011, were included. The influence of tumor type, disease extension, intra-pericardial tumor infiltration on early mortality and long-term survival as well as freedom from symptoms after drainage, and the use of sclerosing agents on PE recurrence rates was analyzed.

Results PE drainage was performed on 46 patients $12 \pm 30$ months after tumor diagnosis. Malignant diseases were lung cancers (50\%), breast cancers (15\%), lymphoma and leukemia (13\%), cancers of the digestive tract (13\%), and others $(9 \%) .80 \%$ of patients were symptomatic and symptom relief was achieved in $65 \%$. Nobody died during surgery. Recurrence rate was $4 \%$. Early in-hospital mortality was $22 \%$. After 1 year, $29 \%$ of patients were alive. Eleven patients $(24 \%)$ had a complete tumor regression. Metastatic spread $(p<0.001)$, pericardial infiltration $(p=0.02)$, and intra-pericardial Bleomycin $(p=0.01)$ injection were associated with increased mortality. Hematological malignancies had a better prognosis for survival.

Conclusion Surgical pericardiotomy is safe, associated with a low recurrence rate and symptom relief in the majority of dyspneic patients. Intra-pericardial Bleomycin may reduce recurrent effusion but does not ameliorate survival. Long-term survival rate was low with an increased mortality in cases of metastatic spreading, pericardial infiltration, and as the tumor of origin: breast cancers. Leukemic and lymphatic tumors have better prognosis.
\end{abstract}

L. Niclauss $(\bowtie) \cdot R$. Prêtre

Department of Cardiac Surgery, University Hospital of Lausanne, 46, rue du Bugnon, 1011 Lausanne, Switzerland e-mail: lars.niclauss@chuv.ch

\section{Montemurro}

Ospedale Bellinzona, Oncology Institute of Southern

Switzerland, Bellinzona, Switzerland

M. Montemurro

Department of Oncology, University Hospital of Lausanne, Lausanne, Switzerland

\section{Introduction}

Surgical pericardial drainage is part of a common and simple standard procedure in the cardiac surgeon's repertoire. Pericardial effusion (PE) due to malignant diseases may be more difficult to handle (intra-pericardial adhesions, tumor infiltration) and patients are therefore frequently admitted for cardiac surgery. The etiologies of PE in neoplasia are many and cardiac surgeons are not necessarily familiar with them. The aim of this retrospective analysis is to evaluate early and late outcomes in terms of morbidity and mortality in PE associated with neoplastic 
Table 1 Demographic and risk factors, etiology in cause comparing long-term survivors with patients died in hospital or during FU

\begin{tabular}{|c|c|c|c|c|}
\hline & $\begin{array}{l}\text { Total }(n=46 / \\
100 \%)\end{array}$ & $\begin{array}{l}\text { Patients died }(n=35 / \\
76 \%)\end{array}$ & $\begin{array}{l}\text { Patients survived }+ \text { TU remission } \\
(n=11 / 24 \%)\end{array}$ & $\begin{array}{l}P\left(\chi^{2} /\right. \\
t \text { test })\end{array}$ \\
\hline Age (years) & $58 \pm 14$ & $58 \pm 14$ & $58 \pm 16$ & 0.64 \\
\hline Gender (male/female) & $26 / 20(57 / 43 \%)$ & $18 / 17$ & $8 / 3$ & 0.21 \\
\hline \multicolumn{5}{|l|}{ Preoperative } \\
\hline $\begin{array}{l}\text { Blood Pressure syst./diast. (mmHg; } \\
\text { median } \pm \text { SD) }\end{array}$ & $\begin{array}{r}115 \pm 20 / \\
75 \pm 12\end{array}$ & $115 \pm 22$ & $120 \pm 14$ & $0.82 /$ \\
\hline Heart rate $(\mathrm{bpm} ;$ median $\pm \mathrm{SD})$ & $105 \pm 14$ & $100 \pm 15$ & $110 \pm 12$ & 0.57 \\
\hline Tachycardia (HR > 100 bpm) & $33(72 \%)$ & $24(69 \%)$ & $9(82 \%)$ & 0.4 \\
\hline Low BMI $\left(<18.5 \mathrm{~kg} / \mathrm{m}^{2}\right)$ & $7(15 \%)$ & $7(20 \%)$ & 0 & 0.11 \\
\hline $\begin{array}{l}\text { Symptoms related to cardiac compression } \\
(\mathrm{n} / \%)\end{array}$ & $37(80 \%)$ & $29(83 \%)$ & $8(72 \%)$ & 0.46 \\
\hline Signs of tamponade at initial echo (n/\%) & $36(72 \%)$ & $27(77 \%)$ & $9(82 \%)$ & 0.74 \\
\hline Metastatic spreading at admission (n/\%) & $28(61 \%)$ & $28(80 \%)$ & 0 & $<0.001$ \\
\hline Pericardial tumor infiltration (n/\%) & $23(50 \%)$ & $22(63 \%)$ & $1(9 \%)$ & 0.02 \\
\hline \multicolumn{5}{|l|}{ Postoperative } \\
\hline $\begin{array}{l}\text { Intra-pericardial Bleomycin injection ( } \mathrm{n} / \\
\%)\end{array}$ & $14(30 \%)$ & $14(40 \%)$ & 0 & 0.01 \\
\hline Symptom relief/amelioration $(\mathrm{n} / \%)$ & $24(52 \% / 65 \% *)$ & $20(57 \% / 69 \% *)$ & $4(36 \% / 50 \% *)$ & 0.23 \\
\hline \multicolumn{5}{|l|}{ TU origin $(\mathrm{n} / \%)$} \\
\hline Lung $(\mathrm{n} / \%)$ & $23(50 \%)$ & $19(54 \%)$ & $4(36 \%)$ & 0.3 \\
\hline Breast $(\mathrm{n} / \%)$ & $7(15 \%)$ & $7(20 \%)$ & 0 & 0.11 \\
\hline Hematologic (n/\%) & $6(13 \%)$ & $1(3 \%)$ & $5(46 \%)$ & $<0.001$ \\
\hline Gastrointestinal (n/\%) & $6(13 \%)$ & $5(14 \%$ & $1(9 \%)$ & 0.66 \\
\hline Others $(\mathrm{n} / \%)$ & $4(9 \%)$ & $3(9 \%)$ & $1(9 \%)$ & 0.96 \\
\hline \multicolumn{5}{|l|}{ TU diagnosis_-PD time } \\
\hline (months $\pm \mathrm{SD} /$ range): all & $12 \pm 30$ & $12 \pm 30$ & $11 \pm 31$ & \\
\hline Lung & $5 \pm 15$ & $5 \pm 17$ & $6 \pm 4$ & \\
\hline Breast & $72 \pm 25$ & $72 \pm 25$ & 0 & \\
\hline Hematologic & $30 \pm 35$ & 1 & $48 \pm 34$ & \\
\hline Gastrointestinal & $47 \pm 31$ & $30 \pm 34$ & 64 & \\
\hline Others & $1 \pm 0.5$ & 1 & 2 & \\
\hline \multicolumn{5}{|l|}{ PD- Survival/FU } \\
\hline (months $\pm \mathrm{SD} /$ range): all & $13 \pm 34$ & $3 \pm 9$ & $60 \pm 37$ & \\
\hline Lung & $8 \pm 27$ & $4 \pm 11$ & $48 \pm 43$ & \\
\hline Breast & $3 \pm 6$ & $3 \pm 6$ & 0 & \\
\hline Hematologic & $51 \pm 49$ & 1 & $66 \pm 44$ & \\
\hline Gastrointestinal & $4 \pm 19$ & $2 \pm 2$ & 52 & \\
\hline Others & $6 \pm 28$ & $5 \pm 3$ & 60 & \\
\hline $\begin{array}{l}\text { Hospital mortality }(\mathrm{n} / \%) /(\text { months } \pm \mathrm{SD} / \\
\text { range) }\end{array}$ & $10(22 \%)$ & \multicolumn{3}{|c|}{$7 \pm 9$ days (range $1-30$ days) } \\
\hline $\begin{array}{l}\text { One-year mortality }(\mathrm{n} / \%) /(\text { months } \pm \mathrm{SD} / \\
\text { range) }\end{array}$ & $28(61 \%)$ & \multicolumn{3}{|c|}{$2 \pm 3$ months (range $1-12$ months) } \\
\hline $\begin{array}{l}\text { FU mortality of initial survivors }(\mathrm{n} / \%) / \\
(\text { months } \pm \mathrm{SD})\end{array}$ & $25(70 \%)$ & \multicolumn{3}{|c|}{$6 \pm 10$ months (range $2-48^{* *}$ months) } \\
\hline $\begin{array}{l}\text { Overall FU mortality }(\mathrm{n} / \%) /(\text { months } \pm \mathrm{SD} / \\
\text { range) }\end{array}$ & $35(76 \%)$ & \multicolumn{3}{|c|}{$3 \pm 9$ months (range $1-48 * *$ months) } \\
\hline
\end{tabular}

Bold values are statistically significant $(p<0.05)$

* Of symptomatic patients, ** 1 pt. died at $48 \mathrm{FU}, 34$ pts. died at $\leq 18$ months FU 
diseases. Tumor origin, presence of pericardial infiltration, and presenting symptoms may be important prognostic factors concerning short- and midterm survival in these high-risk patients.

\section{Methods}

Patients who underwent surgical pericardial drainage, either by a sub-xiphoid approach or by thoracotomy, between January 2001 to December 2011 and who were suffering from malignant diseases, were included. Visualizations of inhomogeneous intra-pericardial structures at echocardiographie (risk of adhesions, TU infiltration), a difficult access for percutaneous drainage, recurrent effusions, or a previous unsuccessful attempt of percutaneous PE drainage were the main criteria for admission to surgery. Echocardiography was carried out in all patients before and after surgery. Hemodynamic instability at admission, cardiac compression, and cardiac function after drainage was recorded. Assessed were in-hospital 30-day mortality and surgical complications (bleeding, prolonged ventilation, severe arrhythmias, and persistent cardiac dysfunction). Recurrent effusion, late mortality, and remission of tumor disease were items of the follow-up (FU). FU was complete. Influence of intra-pericardial tumor cells at PE drainage, underlying tumor burden (metastatic disease other than pericardial), and freedom from symptoms after cardiac decompression were included in the statistical analysis.

\section{Statistical analysis}

The statistical analysis was performed using the SPSS 21.0 statistical software package for Windows (SPSS Inc. Chicago, Illinois, USA). Continuous variables are summarized as median \pm one standard deviation (SD). Categorical variables are presented as numbers and proportions (\%). Chi-square distribution and $t$ test were used for univariate statistical calculation. A $p$ value less than 0.05 was considered to be statistically significant. Kaplan-Meier estimation was used for overall survival estimate. Authors had full access to data and they take responsibility for their integrity.

\section{Results}

From January 2001 to December 2011 a total of 237 patients were admitted for surgical pericardial drainage. Postcardiotomy PE was the main etiology, followed by tumorrelated surgical PE drainage. Forty-six patients underwent surgical PE drainage for malignant disorders. Median age was 58 years (33-86 years). Twenty-six male and 20 female patients underwent a total of 48 pericardiotomies and pericardial fenestrations (two recurrent effusions needed re-intervention). Demographic data are listed in Table 1.

Among the patients, $80 \%(n=37)$ presented with acute symptoms: a recent onset of dyspnea in $70 \%(n=32)$, palpitations in $6 \%(n=3)$, and an inconstant chest pain in $4 \%$ $(n=2)$. The remaining $20 \%(n=9)$ were asymptomatic and $\mathrm{PE}$ was found at $\mathrm{CT}$ scan during routine investigations. FU by echocardiography in these asymptomatic patients confirmed an expanding effusion, requiring PE drainage. Hemodynamic compromise (i.e., right atrial systolic and/or right ventricular diastolic collapse, respiratory volume shift of more than $25 \%$ of the mitral flow) was visualized at preoperative echocardiography in $78 \%(n=36)$ of the patients, all symptomatic. Tachycardia (heart rate at rest of more than 100 beats per minute) at admission was present in $72 \%(n=33$; Table 1).

Malignant diseases were $50 \%$ lung cancers $(n=23)$, $15 \%$ breast cancers $(n=7), 13 \%$ lymphoma and leukemia $(n=6), 13 \%$ gastrointestinal tumors (esophageal, rectal and hepatic cancer; $n=6$ ), and $9 \%$ had other malignancies $(n=4)$.

PE occurred after a median duration of $12 \pm 30$ months (range 1-84 months) after initial tumor diagnosis. Early appearance of PE seems characteristic for lung cancer and rare malignancies, while in other neoplasia PE occurred throughout the disease course, often in relapse (Fig. 1).

Pericardial drainage and fenestration was performed by a sub-xiphoid approach in $81 \%(n=39)$, a small thoracotomy (pleura-pericardial fenestration) in $17 \%(n=8)$. One recurrent effusion required a full sternotomy at re-intervention to optimize intra-pericardial exploration (2\%). No direct surgery-related intra-operative complication (bleeding, perforation, and severe cardiac dysfunction) was observed,

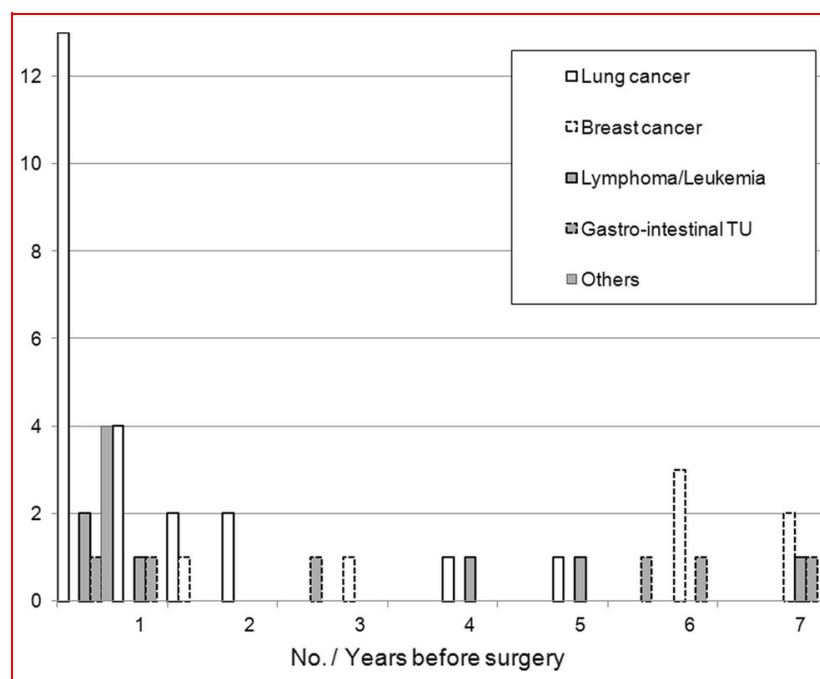

Fig. 1 Distribution of the time delay between initial tumor diagnosis and surgical PE drainage 


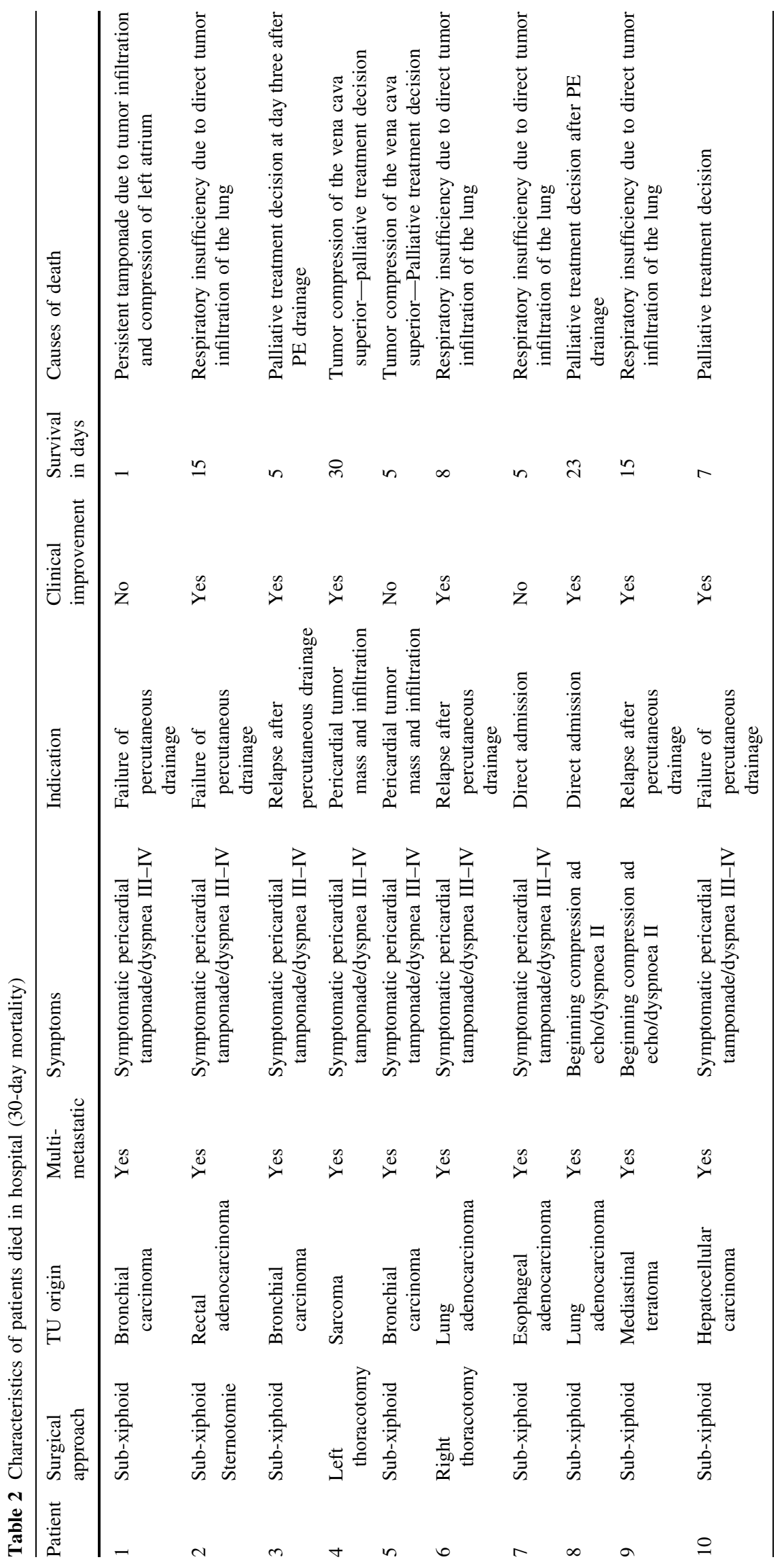




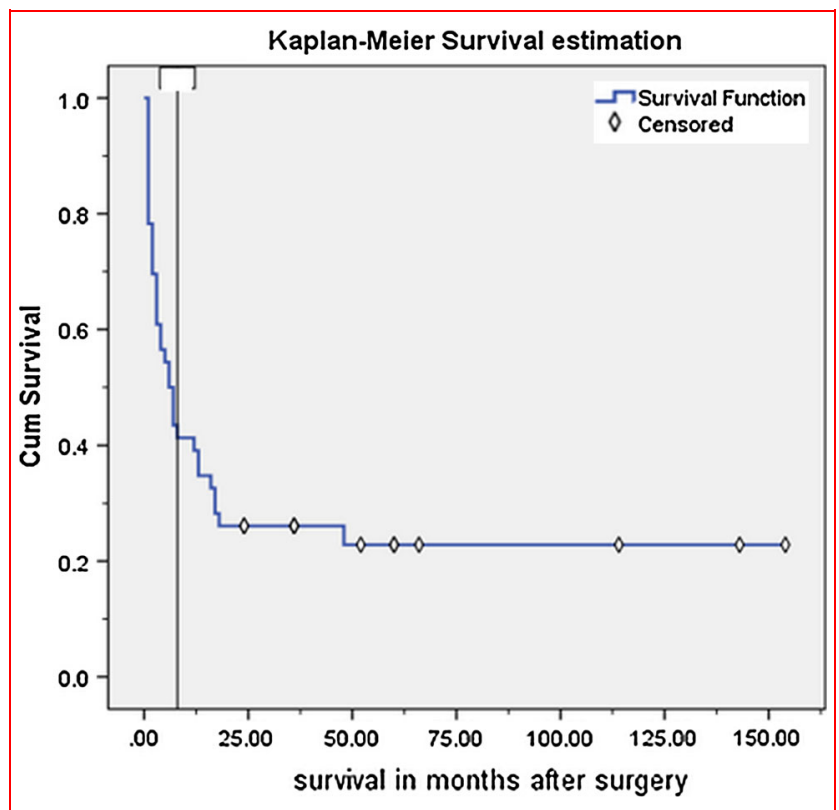

Fig. 2 Kaplan-Meier estimation of survival

and all patients were extubated directly after drainage and pericardial fenestration. Re-operation rate for recurrent effusion was $4 \%$. Two patients were re-operated 4 months after initial surgery. One, requiring the full sternotomy, died in hospital due to severe respiratory failure in the context of an advanced tumor infiltration of both lungs. The second patient died at 1-year FU from his tumor disease.

Nobody died during surgery and all patients left the operating theater alive. The in-hospital 30-day mortality rate was $22 \%(n=10)$. All these patients died in consequence of direct or indirect complications of their advanced tumor disease, after a median of $7 \pm 9$ days after PE drainage (Table 2).

FU was complete for all patients, and median FU was $13 \pm 34$ months. Of the 36 initial survivors, $70 \%(n=25)$ died during a median FU duration of $6 \pm 10$ months (range 2-48; Table 1). None of the deceased patients lived beyond 18 months, except one who died 48 months after surgery. One-year mortality rate was $61 \%$ (Fig. 2).

Systematic pericardial fluid cytology and histopathology of pericardial biopsy confirmed a pericardial tumor infiltration in $50 \%$ of all patients $(n=23)$. None of these patients survived, except one young patient with acute myeloid leukemia who achieved complete remission and was still alive after 10 years (Table 1). Seven patients with pericardial tumor infiltration died $5 \pm 5$ days after surgery, corresponding to $70 \%$ of all patients deceased in-hospital. The remaining 15 patients died after $6 \pm 12$ months. Intrapericardial Bleomycin injection was realized postoperatively in 14 patients with pericardial tumor infiltration, none of these patients had recurrent PE during the survival period.
An advanced disease with metastatic spreading (other than pericardial) at time of $\mathrm{PE}$ drainage $(p<0.001)$, histopathological-proven pericardial tumor infiltration $(p<0.02)$ and concomitant intra-pericardial "Bleomycin injection" $(p<0.01)$ were associated risk factors for mortality (Table 1). A low body mass index (BMI) at time of surgery was (not significantly) associated with increased mortality. Patients with hematological malignancies probably have a better prognosis ( $45 \%$ of all long-term survivors; $p<0.001)$. Other tumor origins did not have a significant impact on survival; however, none of the seven patients with breast cancer survived.

\section{Conclusions}

7-12\% of cancer patients suffering from neoplastic PE may be admitted to cardiac surgery for pericardial drainage [1]. Most common primary tumors are pulmonary cancers, followed by breast cancers and hematological malignancies [24]. Current understanding is that the frequency of PE is mainly determined by tumor biology and anatomic proximity to the heart and pericardium, while origin of the neoplastic disease and response to treatment seem to influence prognosis [5,6]. A systematic analysis of both pericardial fluid and biopsy of the pericardium may increase the detection of intra-pericardial malignant tumor cells [7, 8].

Initial survival of the surgical procedure was not an issue (nobody died in the operating theater); however, an advanced tumor disease, precisely the multi-metastatic spreading at time of PE drainage, was the main contributing factor for the high, 30-day in-hospital mortality rate of $22 \%$. Indications to perform surgical PE drainage in an endstage tumor disease, as a palliative treatment strategy, may be therefore debatable. On the other hand, the fact, that the majority of the patients had at least transitory symptom relief without any direct surgical related complications, may support the role of a little invasive surgery in otherwise nontreatable, severe dyspneic patients (Table 2). The main argument of Patel et al. for opting for a percutaneous prolonged drainage instead of surgical pericardectomy was a significantly lower per-procedural complication rate of the former [2]. Considering that surgical PE drainage and fenestration is a simple, standard surgical procedure, a previously reported surgery-related complication rate of $20 \%$ and recurrence rate of $13 \%$, seem unexpectedly high [2]. In our series, the recurrence rate was only $4 \%$ and postoperative complications were not observed. Secondly, symptom relief or improvement of dyspnea was achieved in $65 \%$ of symptomatic patients.

Low recurrence rate may be due to localized pericardectomy in all and intra-pericardial Bleomycin injection in the majority of the patients, in cases of proven 
intra-pericardial tumor infiltration, as indicated by one randomized trial [3]. Actual guidelines recommend intrapericardial instillation of cytostatic/sclerosing agents in cases of neoplastic effusion and injection may be easily performed by large drainage systems in place [1]. On the other hand, the association of Bleomycin injection with an increased mortality may underline the palliative approach in these, in the large majority, multi-metastatic patients. Its limited anti-neoplastic activity on tumor progression has been reported previously $[3,9]$.

The prognostic value of parameters other than pericardial infiltration and metastatic spreading may be limited. However, we found indicative correlations between tumor origin and mortality. The chance of survival seems to be highest in patients suffering from hematological malignancies. PE in patients with breast cancers all died, probably after long disease progression or relapse, with a median time from tumor diagnosis to surgery of $72 \pm 25$ months (Table 1; Fig. 1).

Present data may reflect a real estimation of successful drainage; concretely, avoidance of recurrent effusion, symptom relief, and overall survival with tumor regression. These parameters are certainly of interest, if a surgical and, in the large majority, mainly palliative procedure is proposed for severely diseased high-risk patients.

A major limitation of the study is the small number of patients observed. Definitive conclusions are difficult to draw, particularly when analyzing the small subgroups with different tumor etiologies.

To resume, the absence of per-operative complications, a low recurrence rate and the improvement of a predominantly severe dyspnea, supports surgical drainage and pericardiotomy as a safe option and a reliable alternative to percutaneous drainage, particularly in recurrent PE or in cases of difficult access. Prognosis was poor, specifically if metastatic spreading and/or direct pericardial tumor infiltration do exist. Hematological cancers may be an etiology with better prognosis. Despite a very low survival rate, surgery remains one important part of the therapeutic armamentarium in these severely diseased, high-risk patients.

\section{References}

1. Maisch B, Seferović PM, Ristić AD, Erbel R, Rienmüller R, Adler Y, Tomkowski WZ, Thiene G, Yacoub MH (2004) Task force on the diagnosis and management of pricardial diseases of the European society of cardiology. Guidelines on the diagnosis and management of pericardial diseases executive summary; the task force on the diagnosis and management of pericardial diseases of the European society of cardiology. Eur Heart J 25:587-610

2. Patel N, Rafique AM, Eshaghian S, Mendoza F, Biner S, Cercek B, Siegel RJ (2013) Retrospective comparison of outcomes, diagnostic value, and complications of percutaneous prolonged drainage versus surgical pericardiotomy of pericardial effusion associated with malignancy. Am J Cardiol 112:1235-1239

3. Kunitoh H, Tamura T, Shibata T, Imai M, Nishiwaki Y, Nishio M, Yokoyama A, Watanabe K, Noda K, Saijo N (2009) A randomised trial of intrapericardial bleomycin for malignant pericardial effusion with lung cancer (JCOG9811). Br J Cancer 100:464-469

4. Sagristà-Sauleda J, Mercé AS, Soler-Soler J (2011) Diagnosis and management of pericardial effusion. World J Cardiol 3:135-143

5. Ishida M, Kagotani A, Iwai M (2014) Cytological features of lung adenocarcinoma with micropapillary pattern in the pleural or pericardial effusion: analysis of 5 cases. Int J Clin Exp Pathol 7:5111-5116

6. Lestuzzi C (2010) Neoplastic pericardial disease: old and current strategies for diagnosis and management. World $\mathrm{J}$ Cardiol 2:270-279

7. Dragoescu EA, Liu L (2013) Pericardial fluid cytology: an analysis of 128 specimens over a 6-year period. Cancer Cytopathol 121:242-251

8. Bardales RH, Stanley MW, Schaefer RF, Liblit RL, Owens RB, Surhland MJ (1996) Secondary pericardial malignancies: a critical appraisal of the role of cytology, pericardial biopsy, and DNA ploidy analysis. Am J Clin Pathol 106:29-34

9. Martinoni A, Cipolla CM, Cardinale D, Civelli M, Lamantia G, Colleoni M, Fiorentini C (2004) Long-term results of intrapericardial chemotherapeutic treatment of malignant pericardial effusions with thiotepa. Chest 126:1412-1416 